\title{
Assessment of Waterlogging Risk in the Deep Foundation Pit Projects Based on Projection Pursuit Model
}

\author{
Han Wu $(1)$ and Junwu Wang (iD \\ School of Civil Engineering and Architecture, Wuhan University of Technology, Wuhan 430070, China \\ Correspondence should be addressed to Junwu Wang; junwuwang@163.com
}

Received 5 February 2020; Accepted 15 May 2020; Published 29 May 2020

Academic Editor: Qiusong Chen

Copyright (c) $2020 \mathrm{Han} \mathrm{Wu}$ and Junwu Wang. This is an open access article distributed under the Creative Commons Attribution License, which permits unrestricted use, distribution, and reproduction in any medium, provided the original work is properly cited.

\begin{abstract}
As a result of global climate change and urbanization, waterlogging disasters have occurred frequently around the world, and deep foundation pit projects with lower terrain suffer even more. This study puts forward a method for the waterlogging risk assessment of deep foundation pit projects via the combination of a projection pursuit model, particle swarm optimization, and an interpolation algorithm. First, through a comprehensive analysis of the water circulation process in waterlogging and the characteristics of deep foundation pit projects, a risk index system with 11 indicators is identified and constructed. Then, a projection pursuit model optimized by particle swarm optimization is leveraged to determine the weights of the indicators and the best projection values of evaluation objects, and the mathematical function between the best projection values and the risk levels is constructed by an interpolation algorithm. Finally, three deep foundation pit projects of the Chengdu Metro Line 11 in China are selected as case studies. The results demonstrate that the frequency of storms, intensity of rainfall, preparation of emergency rescue plans, and proportion of older workers have the greatest impacts on waterlogging risk in deep foundation pits. The risk ranking of the case studies is found to be consistent with the actual situations, which proves the objectivity and effectiveness of the proposed method.
\end{abstract}

\section{Introduction}

In recent years, under the coupled effects of global climate change and urbanization, urban rainstorms and floods have frequently occurred and pose tremendous threats to public safety $[1,2]$. In July 2016, Wuhan, the capital city of Hubei Province in China, suffered a serious waterlogging disaster. This catastrophe caused a direct economic loss of 351 million $\mathrm{RMB}$, and transport and traffic were paralyzed [3]. In January 2020, heavy rain and floods in Jakarta, the capital of Indonesia, resulted in the death of 16 people and the evacuation of 35,600 people. The construction sites of deep foundation pit projects are extremely low; rainwater therefore naturally converges into these pits, making them more vulnerable to waterlogging disasters. Thus, conducting the waterlogging risk assessment of deep foundation pit projects will alleviate the injuries and property losses caused by waterlogging. This is of the highest guiding significance for disaster prevention, mitigation, and preparedness work in the project management of deep foundation pit engineering.

The assessment manner of waterlogging risk is to rate the level of risk via an established mathematical model and evaluation index. According to the key influencing factors of waterlogging disaster risk and different risk levels, project managers are able to implement different measures of waterlogging prevention, mitigation, and preparedness. Scholars have carried out substantial research on urban waterlogging risk assessment. Hou [4] constructed a stormwater management model by combining geographic information system (GIS) and remote sensing (RS) technologies. This model was used to simulate the changes of the inundation range and accumulated water depth with the increase of rainfall intensity in the large-scale area of Jinfeng District, Yinchuan City, China. From the perspective of the discipline of disaster science, Jia et al. [5] studied the risk 
level of waterlogging in prefecture-level cities in Henan, China. The results showed that the ability to prevent and reduce disasters had a critical impact on rainfall and waterlogging risk. Wu et al. [6] investigated the vulnerability of Zhengzhou City to flood disasters from the perspective of government management. Yu et al. [7] used an optimal weighting method and fuzzy comprehensive evaluation method to study waterlogging risk assessment in the construction and operation of subway stations; however, this indicator system was too simple and was unable both to consider the water circulation process during waterlogging and to effectively reflect the characteristics of subway stations. In addition, this study did not incorporate high-dimensional data that could be obtained before evaluation, which reduces the application and popularization values of the proposed model. In summary, existing related research has been primarily focused on large-scale areas such as cities and provinces, rather than small-scale areas such as projects under construction. To the best of the authors' knowledge, research on the assessment of the waterlogging risk in deep foundation pits has not yet been reported.

Currently, soft computing techniques are widely used in risk assessment and have achieved excellent research results. Mikael et al. [8] used the harmony search algorithm to effectively evaluate the geological disasters of railway tunnels. Bui et al. [9] studied the flood forecasting by the multivariate adaptive regression splits and PSO. This paper pointed out that PSO had better reliability and accuracy than other artificial intelligence algorithms. Artificial bee colony algorithm was also used to evaluate the risks of tunnel projects [10].

There are numerous factors that affect the waterlogging risk of deep foundation pits, and waterlogging risk assessment data is therefore high-dimensional. Determining how to effectively deal with this high-dimensional data is the key for improving the objectivity and effectiveness of waterlogging risk assessment. The projection pursuit model (PPM) projects high-dimensional data into low-dimensional space for analysis. In recent years, it has been used increasingly more in the field of risk evaluation [11] and decision-making [12] to effectively evaluate high-dimensional data.

To effectively analyse complex indexes in the research of gas outburst prediction, Liang [13] established a prediction model by using a PPM optimized by a genetic algorithm (GA). In this model, the one-dimensional projection values calculated by the GA were used to indicate the potential gas outburst risk, and the PPM was confirmed to be objective and effective. Liu et al. [14] proposed a PPM improved by the Ameliorative Moth-Flame Optimization (AMFO) algorithm for high-dimensional data for the evaluation and spatial change rule of surface water quality. The empirical analysis results showed that the proposed AMFO-PPE was stable and reliable. To effectively evaluate the sustainability of prefabricated parts, Jiang et al. [15] used a PPM optimized by the Real-code Accelerated Genetic Algorithm (RAGA), based on which a customer satisfaction evaluation algorithm for an e-commerce platform was constructed [16]. According to the previous research results, the key step in the processing of high-dimensional data by a PPM is to determine the optimum projection direction, which is a complex nonlinear optimization problem [17]. At present, most researchers adopt the GA to solve this problem, though it is characterized by some shortcomings including the dependence on the initial population selection, a slow convergence speed, and too many parameter settings $[18,19]$. Compared with a GA and ant colony optimization, particle swarm optimization (PSO), which is also a typical metaheuristic algorithm, is characterized by fast convergence and fewer parameter settings [20]. Although PSO does not require tedious mathematical operations, it has been proven to better solve most optimizations. Dormishi et al. [21] used a variety of metaheuristic algorithms to comprehensively evaluate cutting machine performance in the mineral processing field, and the research results demonstrated that the PSO exhibited advantages over a differential evolution algorithm. Hasanipanah et al. [22] used the PSO model and the other methods to, respectively, predict the ground vibration caused by an explosion; the results also revealed that the PSO model performed better than the other methods.

According to the preceding analysis, the present paper proposes a method of waterlogging risk assessment using the combination of a PPM and PSO. The main contributions of this paper are as follows. (1) From the perspectives of the fields of environmental science and civil engineering, a rainstorm waterlogging disaster risk index system that can reflect the characteristics of small-scale areas in deep foundation pit engineering and construction project management is constructed for the first time. (2) The PPM is used to effectively deal with the problem of the high-dimensional data of rainstorm waterlogging disaster risk, and PSO is used to determine the optimum projection direction of the PPM. (3) This paper, for the first time, reveals that the frequency of storms, intensity of rainfall, preparation of emergency rescue plans, and proportion of older workers have the greatest impacts on the waterlogging risk of deep foundation pits and are the key factors in project management. The series of research in this paper provides a scientific basis for the prevention, mitigation, and preparedness of waterlogging disasters in deep foundation pit engineering.

The remainder of this paper is organized as follows. Section 2 details the research materials and methods, including index selection and the risk assessment method. The process of the case analysis and discussion of the results are presented in Section 3, and the research conclusions are presented in Section 4.

\section{Materials and Methods}

\subsection{The Index System of Waterlogging Risk in Deep Foundation Pits}

2.1.1. Determination of Risk Factors of Waterlogging Risk in Deep Foundation Pits. The risk assessment of waterlogging in deep foundation pits is a complicated and interdisciplinary issue. In the field of environmental science, waterlogging disasters are always provincial; thus, waterlogging risk factors should be considered from the perspective of the 
water cycle process of waterlogging disasters in both deep foundation pits and their surrounding areas [23]. The factors associated with the surrounding area reflect the characteristics of waterlogging disasters in large-scale urban areas, while the factors associated with deep foundation pits reflect the detailed process of waterlogging disasters. The factors that clearly indicate the characteristics of deep foundation pit engineering should then be selected from the perspective of civil engineering; these factors should naturally reflect both structural characteristics and project management characteristics. Finally, the factors related to the capacity of disaster prevention and mitigation should be chosen from the perspective of scientific fields such as disaster management.

In the project management practice of deep foundation pit engineering, many construction and management measures are used to resist waterlogging. For example, a retaining wall along the foundation pit is usually put in place to prevent waterlogging; the higher the height of the retaining wall is, the harder the floods to enter the construction site are, and the less risk of waterlogging there is. Water pumps are also often stored and utilized for draining in deep foundation pits; the more the pumps there are, the faster the water is pumped out and less the risk of waterlogging there is. In addition, the waterlogging risk in deep foundation pit projects is related to the population structure [24]; the public emergency capacity of citizens over 50, namely, the elderly, is significantly hindered; thus, these populations are more vulnerable when faced with emergencies. In other words, the greater the proportion of construction workers over the age of 50, the greater the vulnerability the society has to waterlogging disasters [25] and the higher the risk of waterlogging in deep foundation pit projects.

Referring to previous research results [26, 27], the risk factors associated with disaster prevention and mitigation are the preparation of an emergency rescue plan, efficiency of emergency rescue, proportion of relief workers, and reserve of emergency rescue materials. An emergency rescue plan is the foundation for emergency management when disasters and emergencies occur; the more fully prepared the emergency plan, the stronger the disaster prevention and mitigation capability. The factors related to disaster reduction are divided into two categories, namely, emergency rescue support factors and emergency rescue organization factors. Copious professional rescue personnel and sufficient relief materials are the foundations of successful emergency response work. When natural disasters such as waterlogging occur, the more complete the emergency rescue organization, the faster the information communication, and the higher the efficiency of emergency rescue.

2.1.2. Construction of Evaluation Index System. Taking fully into account objectivity, systematism, availability, and independence, risk indicators that are representative of all risk factors identified in Section 2.1.1 were chosen in this study. An evaluation index system including 11 risk indicators was constructed, as presented in Table 1.

In Table $1, \mathrm{X} 1, \mathrm{X} 2, \mathrm{X} 3, \mathrm{X} 5, \mathrm{X} 6, \mathrm{X} 7$, and $\mathrm{X} 10$ are quantitative indicators, and their data was obtained by field research and the review of local water resources announcements, local yearbooks, etc. Considering the unavailability of partial data in current engineering practice, $\mathrm{X} 4, \mathrm{X} 8, \mathrm{X} 9$, and $\mathrm{X} 11$ are all qualitative indexes without measurement units, and their scores were obtained by a questionnaire survey. X1, X2, X3, and X7 are benefit-based indicators; the greater the numerical values of these indicators, the greater the level of waterlogging risk. The remaining indicators are cost-based; the smaller the numerical values, the greater the level of waterlogging risk.

\subsubsection{Assessment Standard of Waterlogging Risk.} Currently, there are no uniform standards for the assessment of waterlogging risk $[28,29]$. To meet the needs of deep foundation pit project management practice, the risk assessment levels in this study were classified by the different risk response measures that should be taken. Four levels of waterlogging risk, namely, low risk (I), moderate risk (II), high risk (III), and extreme risk (IV), were identified. The low risk (I) category denotes that there is no need to take further measures, only to check how existing measures are implemented. Moderate risk (II) indicates that additional measures should be developed to deal with the risk of waterlogging. High risk (III) implies that there is no need to stop the construction operation, but further measures must be immediately formulated to reduce the level of waterlogging risk as soon as possible. Extreme risk (IV) signifies that the construction task must be suspended immediately and that project managers are obliged to promptly take measures to decrease the waterlogging risk level.

As indicated in Table 1, the standards of different evaluation levels for the 11 indicators were established by combining the expert experience of project managers and previous research results [30, 31]. The risk level descriptions of the four qualitative indicators, $\mathrm{X} 4, \mathrm{X} 8, \mathrm{X} 9$, and $\mathrm{X} 11$, are divided into 2 components, namely, the qualitative language description and corresponding quantitative score range. For example, the low risk (I) level of X8 is "fully sufficient [90, 100];" "fully sufficient" is a qualitative language description, and " $90-100$ " is the corresponding quantitative score range. If an expert judged from experience that the situation of the X8 index to be evaluated was fully sufficient, it would have been scored to be between 90 and 100 in the questionnaire.

It must be pointed out that, to the best of the authors' knowledge, there has been no study on the upper limit values of X1, X2, X3, X5, and X6. To better generalize the index system, the upper limits of these indexes are " $+\infty$ " in Table 1 . When this index system was used to carry out case studies, their upper limit values would have been reasonably selected in combination with deep foundation pit engineering practice, rather than being considered to be $+\infty$.

\subsection{Risk Assessment Method of Waterlogging Risk in the Deep Foundation Pits}

2.2.1. Projection Pursuit Model. The PPM is a statistical method for processing and analysing high-dimensional data. The method was originally coined by Friedman and Tukey 
TABLE 1: The index system of waterlogging risk in the deep foundation pit projects.

\begin{tabular}{|c|c|c|c|c|c|}
\hline Indicator level & Unit & I & II & III & IV \\
\hline $\begin{array}{l}\text { Intensity of rainfall } \\
\mathrm{X} 1\end{array}$ & $\mathrm{~mm} / 24 \mathrm{~h}$ & {$[0,50)$} & {$[50,100)$} & {$[100,250)$} & {$[250,+\infty)$} \\
\hline $\begin{array}{l}\text { Frequency of storms } \\
\mathrm{X} 2\end{array}$ & times/year & {$[0,1)$} & {$[1,3)$} & {$[3,6)$} & {$[6,+\infty)$} \\
\hline $\begin{array}{l}\text { Distance to urban drains } \\
\mathrm{X} 3\end{array}$ & $\mathrm{~m}$ & {$[0,50)$} & {$[50,200)$} & {$[200,500)$} & {$[500,+\infty)$} \\
\hline $\begin{array}{l}\text { Surrounding environment } \\
\mathrm{X} 4\end{array}$ & - & $\begin{array}{c}\text { No } \\
{[90,100]}\end{array}$ & $\begin{array}{c}\text { Few } \\
{[75,90)}\end{array}$ & $\begin{array}{l}\text { Moderate } \\
{[60,75)}\end{array}$ & $\begin{array}{l}\text { Many } \\
{[0,60)}\end{array}$ \\
\hline $\begin{array}{l}\text { Height of retaining wall } \\
\mathrm{X} 5\end{array}$ & $\mathrm{~m}$ & {$[1.2,+\infty)$} & {$[0.6,1.2)$} & {$[0.3,0.6)$} & {$[0,0.3)$} \\
\hline $\begin{array}{l}\text { Number of pumps } \\
\text { X6 }\end{array}$ & $/ 100 \mathrm{~m}^{2}$ & {$[0.5,+\infty)$} & {$[0.2,0.5)$} & {$[0.1,0.2)$} & {$[0,0.1)$} \\
\hline $\begin{array}{l}\text { Proportion of older workers } \\
\text { X7 }\end{array}$ & $\%$ & {$[0,5)$} & {$[5,10)$} & {$[10,20)$} & {$[20,100]$} \\
\hline $\begin{array}{l}\text { Preparation of emergency rescue plans } \\
\text { X8 }\end{array}$ & - & $\begin{array}{l}\text { Fully sufficient } \\
\quad[90,100]\end{array}$ & $\begin{array}{l}\text { Sufficient } \\
{[75,90)}\end{array}$ & $\begin{array}{l}\text { Basically insufficient } \\
{[60,75)}\end{array}$ & $\begin{array}{l}\text { Insufficient } \\
{[0,60)}\end{array}$ \\
\hline $\begin{array}{l}\text { Efficiency of emergency rescue } \\
\text { X9 }\end{array}$ & - & $\begin{array}{c}\text { Fully efficient } \\
\quad[90,100]\end{array}$ & $\begin{array}{l}\text { Efficient } \\
{[75,90)}\end{array}$ & $\begin{array}{c}\text { Basically efficient } \\
{[60,75)}\end{array}$ & $\begin{array}{l}\text { Inefficient } \\
{[0,60)}\end{array}$ \\
\hline $\begin{array}{l}\text { Proportion of relief workers } \\
\text { X10 }\end{array}$ & $\%$ & {$[30,100]$} & {$[20,30)$} & {$[10,20)$} & {$[0,10)$} \\
\hline $\begin{array}{l}\text { Situation of emergency relief supplies } \\
\text { X11 }\end{array}$ & - & $\begin{array}{l}\text { Fully efficient } \\
\quad[90,100]\end{array}$ & $\begin{array}{l}\text { Efficient } \\
{[75,90)}\end{array}$ & $\begin{array}{c}\text { Basically efficient } \\
{[60,75)}\end{array}$ & $\begin{array}{l}\text { Inefficient } \\
{[0,60)}\end{array}$ \\
\hline
\end{tabular}

from Stanford University in 1974 [32]. The basic idea is tantamount for projecting high-dimensional data into a lowdimensional space. Therefore, this model can effectively eliminate variable interference that is not related to the data structure. Additionally, the objective weights of the indicators were computed directly from the characteristics of the sample data [33] in their application to system evaluation.

The general steps of the PPM used in the system evaluation are as follows.

\section{(1) Standardization of Data}

Let the indicator sequence be $\left[\mathbf{x}_{i j}\right]_{m \times n}$, where $m$ is equal to the number of samples and $n$ is the number of indicators.

To eliminate the dimensional impact of the evaluation indicators and ensure the generalizability of the modelling, the extreme value normalization method was employed in this study to standardize the data.

The benefit-based indicators [34] are as follows:

$$
x_{i j}^{*}=\frac{x_{i j}-\min \left(x_{j}\right)}{\max \left(x_{j}\right)-\min \left(x_{j}\right)},
$$

and the cost-based indicators [34] are as follows:

$$
x_{i j}^{*}=\frac{\max \left(x_{j}\right)-x_{i j}}{\max \left(x_{j}\right)-\min \left(x_{j}\right)},
$$

where $x_{i j}^{*}$ indicates the value of the evaluation index after standardization, $\max \left(x_{j}\right)$ represents the maximum value of indicator $j$, and $\max \left(x_{j}\right)$ represents the minimum value of indicator $j$.

\section{(2) Construction of Projection Indicator Function}

The core idea of the PPM is to project $\left[\mathbf{x}_{i j}^{*}\right]_{m \times n}$ to obtain the projection value $z(i)$ according to projection indicators $=\left(a_{1}, a_{2}, \cdots, a_{m}\right)$ [35]. The projection indicator function is

$$
\mathbf{Z}(i)=\sum_{j=1}^{m} a_{j} x_{i j}^{*}
$$

Optimizing a requires that the distribution characteristics of $\mathbf{Z}(i)$ are such that the projection points are locally as dense as possible and overall spread out as much as possible. Therefore, the best projection direction is determined by maximizing the product of the standard deviation and the local density. The optimal projection function [36] is

$$
S_{z}=\sqrt{\frac{\sum_{i=1}^{n}(\mathbf{Z}(i)-E(z))^{2}}{n-1}},
$$

where $S_{z}$ is the standard deviation of $\mathbf{Z}(i)$ and $E(z)$ is the average of $\mathbf{Z}(i)$.

$$
D_{z}=\sum_{i=1}^{n} \sum_{j=1}^{m}\left(R-r_{i j}\right) u\left(R-r_{i j}\right),
$$

where $D_{z}$ is the local density of $\mathbf{Z}(i), r_{i j}$ is the distance between samples, $R$ is the window radius of the local density, and it is also the only parameter set in the PPM. Additionally, $u\left(R-r_{i j}\right)$ is the unit step function. When $R-r_{i j} \geq 0, u\left(R-r_{i j}\right)=1$; otherwise, $u\left(R-r_{i j}\right)=0$.

(3) Optimizing the Projection Index Function

When the indicator sample set $\left[\mathbf{x}_{i j}\right]_{m \times n}$ is determined, $\mathbf{Q}(a)$ only changes with the projection direction a. If the projection direction is the best projection direction $\mathbf{a}^{*}, \mathbf{Q}(a)$ must be at the maximum value. The low-dimensional data obtained in the best projection direction $\mathbf{a}^{*}$ can be best explained by the characteristic structure of the original data [37].

Based on the preceding analysis, the method of finding the maximum value of the projection index function was employed to find the best projection direction. 
The function to maximize the objective is [38]

$$
\max \mathbf{Q}(a)=S_{z}\left|D_{z}\right|,
$$

and the constraint is

$$
\sum_{j=1}^{m} a_{j}^{2}=1, \quad 0 \leq a_{j} \leq 1 .
$$

\section{(4) Solving the Optimum Projection Direction}

Equations (6) and (7) are utilized to compute the optimal projection vector. Generally, most scholars would use GA $[13,15,16]$ and other algorithms for the solution. However, the GA has drawbacks, including the computing result having certain dependence on the initial population selection, its slow convergence speed, and its excessive parameter settings $[18,19]$. In contrast, PSO is characterized by advantages including a fast convergence speed and fewer parameter settings [20-22, 39]; thus, PSO was employed in the present study to find the best projection vector $\mathbf{a}^{*}$.

By substituting $\mathbf{a}^{*}$ into (3), the projection vector $\mathbf{Z}^{*}(i)$ can be solved.

2.2.2. Particle Swarm Optimization. PSO is a group-based random search algorithm that is designed by simulating the predation behaviour of bird swarms. Its basic idea is to start from a random solution, find the optimal solution through iteration, and then evaluate and determine the optimal solution through fitness.

In each iteration of PSO, a particle updates its own position by tracking the individual optimal solution and the group optimal solution, thereby constantly adjusting its position to approach the optimal position.

Let the population size of the particles be $N$; the velocity update formula of the particle $b$ is as follows:

$$
v_{b}(t+1)=\omega v_{b}(t)+c_{1} r\left[q_{b}(t)-a_{b}(t)\right]+c_{2} r\left[g(t)-a_{b}(t)\right] .
$$

The velocity update formula is as follows:

$$
a_{b}(t+1)=a_{b}(t)+v_{b}(t+1),
$$

where $\omega$ is the inertia weight factor, $c_{1}$ and $c_{2}$ are the learning factors, $r$ is a random number within the interval $[0,1], q$ is the individual optimal value, and $g$ is the global optimum value.

After reaching a certain condition in which the iteration terminates, the best projection vector $\mathbf{a}^{*}$ is obtained by the position of the particle swarm aggregation.

2.2.3. Risk Assessment Method Construction. The flow chart of this evaluation method is illustrated in Figure 1.

The specific steps of the construction of the risk assessment method based on the PPM are as follows.

Step 1. Preparing Data

(1) According to Table 1, the random sampling method is used to generate the standard sample set $\left[\mathbf{x}_{i j}\right]_{p \times n}$, where $p$ is the number of standard samples obtained by the random sampling method. Equation (1) or (2) is leveraged to normalize it to obtain $\left[\mathbf{x}_{i j}^{*}\right]_{p \times n}$. To ensure the accuracy and stability of subsequent interpolation function models, hundreds of standard sample sets are extracted, so $\left[\mathbf{x}_{i j}^{*}\right]_{p \times n}$ is always highdimensional data. Because the standard sample set $\left[\mathbf{x}_{i j}\right]_{p \times n}$ is generated according to the random sampling method, the risk levels $\mathbf{Y}_{1}(i)$ are also known.

(2) Field research, theoretical computing, and questionnaires were used to obtain the evaluation indicator set of the research object $\left[\mathbf{x}_{i j}\right]_{m \times n}$. According to the characteristics of each indicator, (1) or (2) is adopted to standardize it and subsequently obtain $\left[\mathbf{x}_{i j}^{*}\right]_{m \times n}$.

Step 2. Calculating the Weights and Projection Values by the PPM and PSO

(1) $\left[\mathbf{x}_{i j}^{*}\right]_{p \times n}$ and $\left[\mathbf{x}_{i j}^{*}\right]_{m \times n}$ are combined into a computing set $\left[\mathbf{x}_{i j}^{*}\right]_{(m+p) \times n}$. The projection index function $\mathbf{Z}(i)$ is constructed according to (3).

(2) Equations (4) and (5) are used to find the maximum objective function $\mathbf{Q}(a)$, and PSO is utilized to solve the function $\mathbf{Q}(a)$.

(3) When the PSO reaches the convergence condition, the optimal projection direction $\mathbf{a}^{*}$ is obtained. $\mathbf{Z}(i)$ is then computed, where $i=1,2,3, \cdots, m+p$. The projected value $Z_{1}(i)$ of the standard sample set $\left[\mathbf{x}_{i j}^{*}\right]_{p \times n}$ and the projected value $\mathbf{Z}_{2}(i)$ of the evaluation indicator set $\left[\mathbf{x}_{i j}^{*}\right]_{m \times n}$ are both included in $\mathbf{Z}(i)$.

(4) Every element of $\mathbf{a}^{*}$ is squared to obtain the objective weight of each index [35].

Step 3. Obtaining Evaluation Levels by the Interpolation Algorithm

(1) According to the projection value of the standard sample set $\mathbf{Z}_{1}(i)$ and its default risk level $\mathbf{Y}_{1}(i)$, the interpolation method is used to construct the mathematical model of risk assessment as follows [40]:

$$
\mathbf{Y}=f\left(\mathbf{Z}_{1}\right)
$$

(2) By introducing the projection value of the evaluation sample set $\mathbf{Z}_{2}(i)$ into the mathematical model $\mathbf{Y}=f\left(\mathbf{Z}_{1}\right)$, the waterlogging risk level of each evaluation sample is computed.

From these steps, it is evident that this method is directly motivated by data. Compared with functional mode evaluation methods, such as fuzzy comprehensive evaluation, the proposed method effectively avoids the difficulty of constructing the functional relationship between the evaluation index set and evaluation level.

\section{Results and Discussion}

3.1. Engineering Background. The Chengdu Metro Line 11 project involves a total investment of about 16.5 billion yuan. 


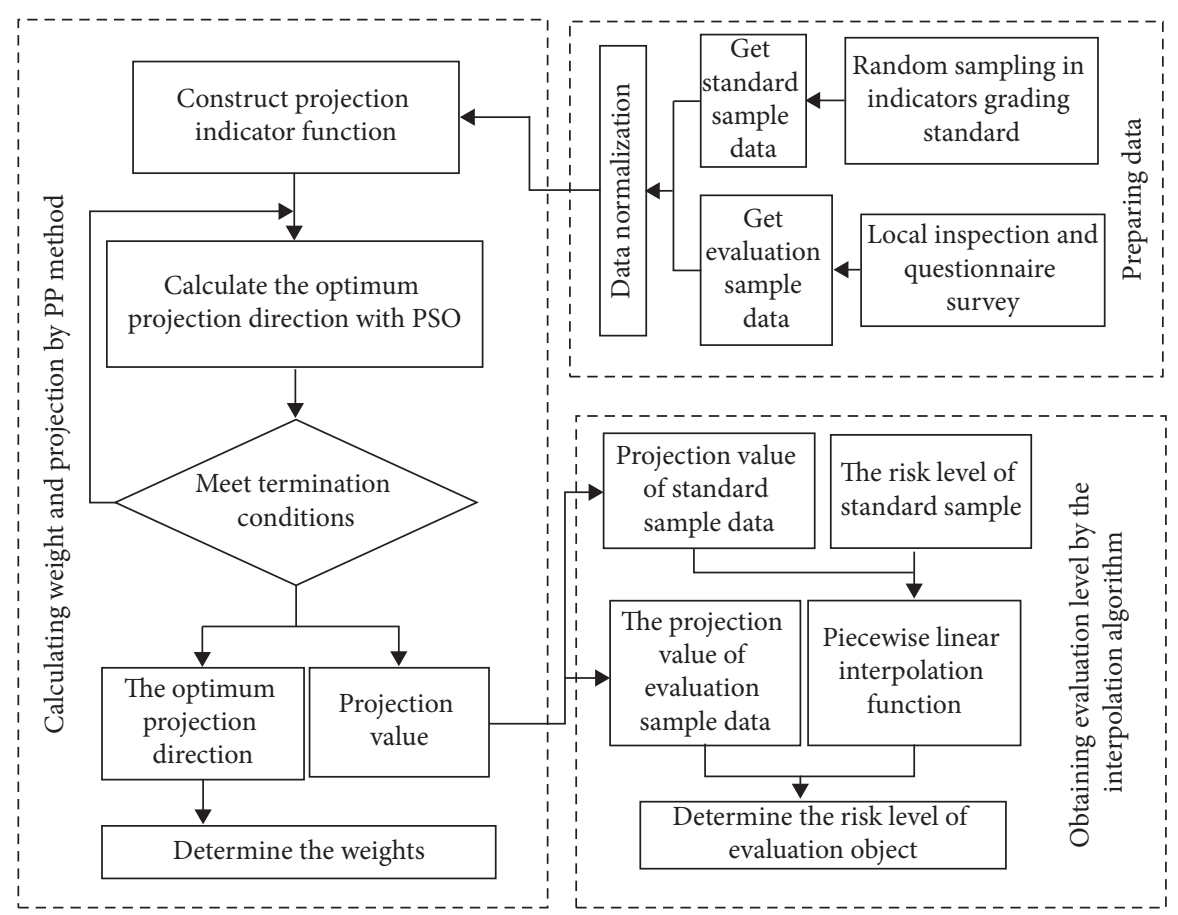

FIgURE 1: Flow chart of the waterlogging risk evaluation method based on the PPM.

It is about $22 \mathrm{~km}$ in length and comprises 22 station projects. This major project traverses the Chengdu Hi-tech Zone, Tianfu New District, and Shuangliu District. The landform features are mostly plains, platforms, or a small number of low hills. The average annual rainfall in Chengdu is $879.3 \mathrm{~mm}$, and the maximum rainfall in $24 \mathrm{~h}$ is $167.6 \mathrm{~mm}$. Waterlogging and droughts often occur in Chengdu.

The deep foundation pit projects of Diaoyuzui Station, Tianfu CBD North Station, and Xinchuan Science Park East Station were selected as a case study. The platforms of these three stations are two-story islands. The deep foundation pits were all constructed by the open-cut method, and there are no adverse geological effects or special geotechnical soil within their construction scopes. However, among all 22 station projects on Chengdu Metro Line 11, these three projects have the following differences.

(1) The construction company used for Diaoyuzui Station and Xinchuan Science Park East Station, China Construction Third Bureau Group Co., Ltd., has rich experience in subway construction; however, the construction company used for Tianfu CBD North Station is China Railway Investment and Construction Co., Ltd., which lacks experience in subway.

(2) Diaoyuzui Station, which is located in the suburban countryside, has almost no urban drains in its surrounding area, which is characterized by environmental elements that are prone to waterlogging, such as flood canals and high slopes. Tianfu CBD North Station is located in the CBD area that is under construction, where the municipal drains are well developed and there are no adverse environmental elements. Xinchuan Science Park East Station is situated in the suburban development zone, in which there are fish ponds and a large number of gas pipelines.

(3) Diaoyuzui Station is the largest station on Chengdu Metro Line 11, with a total length of $340.40 \mathrm{~m}$, a total width of $21.5 \mathrm{~m}$, and an excavation depth of 16.9-27.3 $\mathrm{m}$, all of which are the largest among the three case study stations. Xinchuan Science Park East Station is the smallest.

3.2. Sources of Data. Based on the hydrological and meteorological characteristics of Chengdu and the 22 deep foundation pit projects of Chengdu Metro Line 11, the upper limit values of X1, X2, X3, X5, and X6 were, respectively, determined to be $500,12,3000,2.4$, and 1 .

The quantitative indicator scores of these three deep foundation pits were obtained by consulting the Chengdu Water Resources Announcement, the project management documents of the Chengdu Metro Line 11 project, and field surveys. Their scores are presented in Table 2. The scores of the quantitative indexes X4, X8, X9, and X11 were obtained from a questionnaire survey of ten experts.

Among the ten experts, three were from universities, two were from construction companies, and five were from subway construction units. Seven experts had the title of senior engineer or above, and the other three experts had titles of associate senior engineer or associate professor. Six experts were well aware of construction safety risks and have produced related research. Seven experts were familiar with the construction of Chengdu Metro Line 11 and participated in the construction of the project. SPSS 22 software was used 
TABLE 2: Indicators' scores of three evaluation objects.

\begin{tabular}{lcccc}
\hline Indicator & $\begin{array}{c}\text { Diaoyuzui } \\
\text { Station }\end{array}$ & $\begin{array}{c}\text { Tianfu CBD North } \\
\text { Station }\end{array}$ & $\begin{array}{c}\text { Xinchuan Science and Technology } \\
\text { Park }\end{array}$ & Data sources \\
\hline X1 & 167.6 & 167.6 & 167.6 & $\begin{array}{c}\text { Chengdu Water Resources } \\
\text { Announcement } \\
\text { X2 }\end{array}$ \\
Chengdu Water Resources \\
Announcement \\
X3 & 3.125 & 3.125 & 3.125 & Field research \\
X5 & 2600 & 150 & 50 & Field research and questionnaire survey \\
X6 & 13.5 & 31 & 92 & Field research \\
X7 & 0.6 & 1 & 0.4 & Field research \\
X8 & 0.11 & 9.11 & 11.72 & Field research \\
X9 & 8.61 & 33 & 46.5 & Field research and questionnaire survey \\
X10 & 73 & 70.5 & 80 & Field research and questionnaire survey \\
X11 & 19.95 & 10.87 & 19.01 & Field research \\
& 73 & 72.5 & 79.5 & Field research and questionnaire survey \\
\hline
\end{tabular}

to test the reliability of this questionnaire. The value of Cronbach's $\alpha$ was found to be 0.743 and therefore met the reliability requirement of a questionnaire survey [41]; thus, the results of this questionnaire survey were reliable. The average of the scoring results of the 10 experts was the scores of these quantitative indicators.

3.3. Mathematical Risk Assessment Model with the Interpolation Algorithm. According to Table 1 and Figure 1, 100 standard evaluation objects in each risk level were generated by the random sampling method [39]. Thus, there were 400 standard evaluation objects obtained for the establishment of a mathematical model of risk evaluation. The data of these 400 standard evaluation objects (the standard sample data in Figure 1) and the data of 3 units to be assessed (the evaluation sample data in Figure 1) were substituted into a selfprogrammed program based on MATLAB R2016a software. Referring to previous research results [42-45], the swarm size was 200, the personal learning coefficient and global learning coefficient were both 2 , the inertia weights decreased linearly from 0.9 to 0.4 , the minimum acceptance accuracy was 0.00001 , and the maximum number of iterations was 1000. Although the minimum accuracy requirement was met when the iteration number reached about 200 in the case analysis, the population number and the maximum iteration number were set to be relatively large in this study to ensure that the model could calculate more complex problems. The convergence curve of the 1000 iterations is presented in Figure 2.

Following the optimization calculation process of PSO, the error between the 194th iteration and 195th iteration was greater than the minimum acceptance precision (0.00001), and the error between the 195th iteration and 196th iteration was less than that of the minimum acceptance precision stage. After that, the errors of the calculation results were all less than 0.00001. Based on the calculation termination conditions of the algorithm, the calculation was arrested at the 1000th iteration with a very small error. These findings indicate that the PSO algorithm found the best projection vector at the 196th iteration, which is illustrated by both Figure 2 and Table 3.

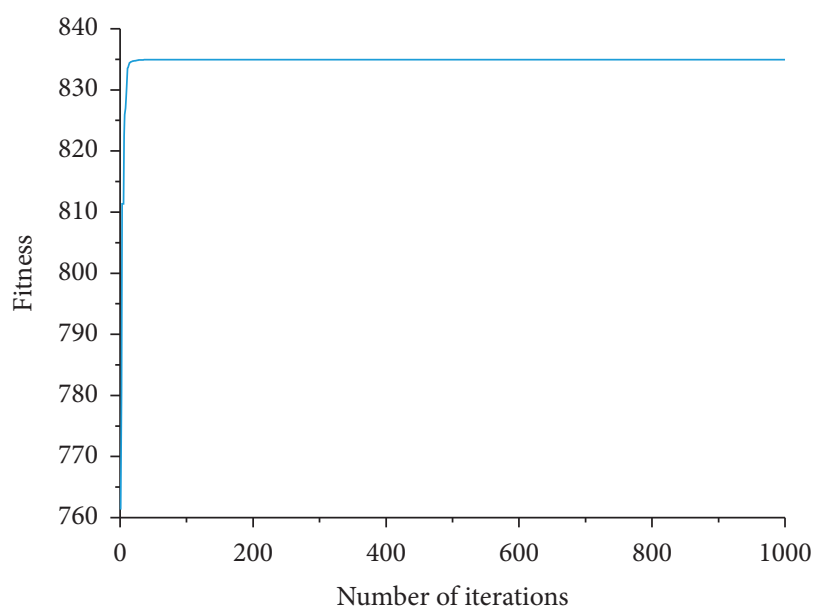

FIgURE 2: The convergence curve of the PPM optimized by PSO.

After calculation, the best projection direction $\mathbf{a}^{*}$ was found to be $(0.3642,0.3784,0.3225,0.3207,0.1765,0.1887$, $0.3340,0.3481,0.31860,0.1004,0.3258)$. The scatter diagram of the projection values $\mathrm{Z}_{1}(i)$ of 400 standard evaluation objects and the corresponding risk level $\mathbf{Y}_{1}(i)$ is presented in Figure 3.

As exhibited in Figure 3, the scatter diagram of the best projection values and risk levels was a ladder-type and was characterized by an increasing curve; the larger the projection value, the greater the waterlogging risk. The projection values were aggregated rather than being continuously distributed. This graphic feature was determined by the basic idea of the PPM. Locally, the optimized projection points should be clustered as much as possible. On the whole, they should be spread as much as possible. This clustering phenomenon presented in Figure 3 was fairly consistent with the results of previous classical literature [46], and Figure 3 further demonstrates that the PPM utilized in this study had been optimized.

The maximum projection value in the low risk (I) level was 0.3818 . The maximum projection value in the moderate risk (II) level was 0.8562 , and the minimum projection value was 0.6079 . The maximum projection value in the high risk 
TABle 3: Precision level and calculation termination in the 1000th iteration.

\begin{tabular}{lcccc}
\hline Iteration $(n)$ & Fitness $(n-1)$ & Fitness $(n)$ & Fitness $(n)-$ Fitness $(n-1)$ & Result \\
\hline 194 & 834.956821 & 834.956821 & $0<0.00001$ & Continue \\
195 & 834.956821 & 834.956841 & $0.0000197>0.0001$ & Continue \\
196 & 834.956841 & 834.956841 & $0<0.0001$ & Continue \\
1000 & 834.956842 & 834.956842 & $0<0.0001$ & Stop \\
\hline
\end{tabular}

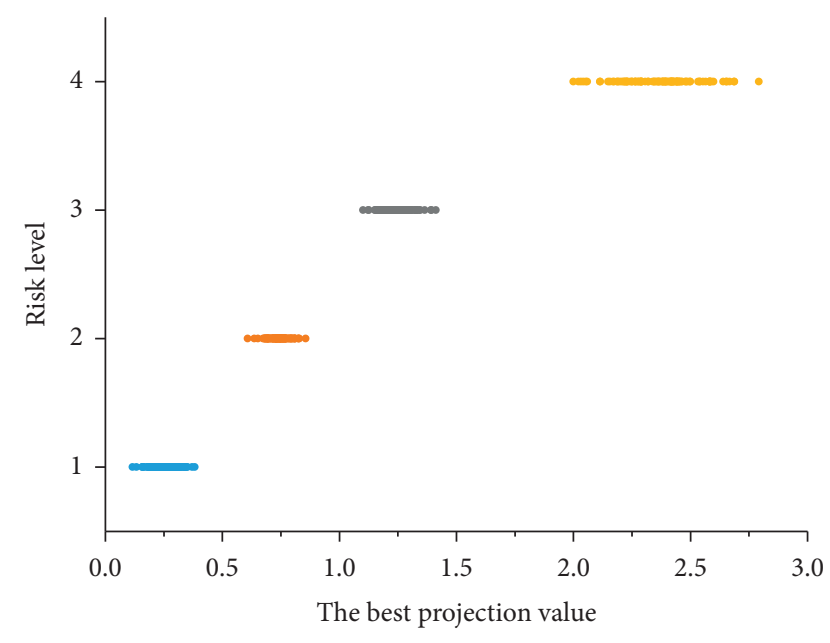

FIGURE 3: Scatter diagram of the standard evaluation object projection values and risk levels.

(III) level was 1.4125 , and the minimum projection value was 1.1010. The minimum projection value in the extreme risk (IV) level was 1.9991. Using the piecewise linear interpolation method, a mathematical model for the waterlogging risk assessment of deep foundation pit engineering was established:

$$
y(i)=\left\{\begin{array}{lc}
1, & z^{*} \leq 0.3818 \\
1+\frac{z^{*}-0.3818}{0.6079-0.3818}, & 0.3818<z^{*}<0.6079 \\
2, & 0.6079 \leq z^{*} \leq 0.8562 \\
2+\frac{z^{*}-0.8562}{1.1010-0.8562}, & 0.8562<z^{*}<1.1010 \\
3, & 1.1010 \leq z^{*} \leq 1.4125 \\
3+\frac{z^{*}-1.4125}{1.9991-1.4125}, & 1.4125<z^{*}<1.9991 \\
4, & z^{*} \geq 1.9991
\end{array}\right.
$$

3.4. Analysis and Discussion. This section analyses and discusses the calculation results of the weights and risk levels in detail. However, the waterlogging risk evaluation index system presented in this work was constructed from the perspectives of environmental science and civil engineering; if this research had been carried out from the perspectives of other disciplines, the index system and calculation results of the weights and risk levels would have been different. Due to the lack of academic research on the waterlogging risk assessment of deep foundation pit engineering, the calculation results are primarily compared and discussed with the actual disaster situation of Chengdu Metro Line 11 in the 2018 flood season. In addition, while the PSO was successfully employed to optimize the PPM in the present case study, many other optimization calculation methods could be applied for the optimization of the PPM. Depending on the results of the case analysis, this section also presents detailed measures suggested for addressing the waterlogging risk in deep foundation pit engineering.

3.4.1. Weight Analysis. After squaring each element in the calculated optimal projection direction [35], namely (0.3642, $0.3784,0.3225,0.3207,0.1765,0.1887,0.3340,0.3481$, $0.31860,0.1004,0.3258)$, the objective weights of the 11 indicators were calculated and are presented in Table 4 .

From Table 4, it is evident that X2 (frequency of storms) and X1 (intensity of rainfall) had the greatest impacts on the risk of waterlogging in deep foundation pit engineering. These results were similar to the calculation results of a previous study [47]. From the perspective of disaster science, $\mathrm{X} 1$ and $\mathrm{X} 2$ were found to be the greatest indicators, which demonstrates that disaster-causing factors have the greatest impacts on waterlogging risk.

The weight of X8 ranked third and was also the largest among the indicators related to disaster prevention and mitigation. This further demonstrates that emergency rescue plans form the basis of emergency management. The weight of X7 (proportion of older workers) ranked fourth and therefore also has a great influence on the waterlogging risk. It is worth noting that the superior weight of X7 might be closely related to the aging phenomenon of Chinese construction workers in the past decade.

The weight analysis results were found to be in agreement with the actual disaster situation of the deep foundation pit project of Diaoyuzui Station during the flood season of 2018. At the beginning of July 2018, a series of torrential rainstorms in Chengdu led to the inflow of water in the deep foundation pit of Diaoyuzui Station. When the waterlogging disaster occurred, the project managers prioritized saving lives, so the workers at the construction site and in the living area, especially the older workers, were first evacuated, resulting in a delay in the rescue of the site, thereby enlarging the disaster losses. 
TABLE 4: Weights and rankings of all risk indicators.

\begin{tabular}{lccccccccccc}
\hline Indicator & $\mathrm{X} 1$ & $\mathrm{X} 2$ & $\mathrm{X} 3$ & $\mathrm{X} 4$ & $\mathrm{X} 5$ & $\mathrm{X} 6$ & $\mathrm{X} 7$ & $\mathrm{X} 8$ & $\mathrm{X} 9$ & $\mathrm{X} 10$ & $\mathrm{X} 11$ \\
\hline Weight & 0.1327 & 0.1432 & 0.1040 & 0.1029 & 0.0312 & 0.0356 & 0.1116 & 0.1212 & 0.1015 & 0.0101 & 0.1061 \\
Ranking & 2 & 1 & 6 & 7 & 10 & 9 & 4 & 3 & 8 & 11 & 5 \\
\hline
\end{tabular}

Based on these results, some advice is provided for project managers regarding the carrying out of the risk management and decision-making related to waterlogging disasters in deep foundation pit projects; focus should be placed on X2 (frequency of storms), X1 (intensity of rainfall), X8 (preparation of emergency rescue plans), and X7 (proportion of older workers), while the investment of resources in factors X5, X6, and X10 should be of secondary concern.

3.4.2. Risk Level Analysis. The best projected values for the deep foundation pit projects of Diaoyuzui Station, Tianfu CBD North Station, and Xinchuan Science Park East Station were found to be 1.4524, 1.3275, and 1.0644, respectively. By substituting these values into (11), the respective risk levels were determined to be $3.0681,3.0000$, and 2.8505 . The waterlogging risk level of the Diaoyuzui Station was between the high risk (III) and the extreme risk (IV) levels. The waterlogging risk in Tianfu CBD station was at the high risk (III) level and that of Xinchuan Science Park East Station was between the moderate risk (II) and high risk (III) levels. Thus, the waterlogging risks in these three deep foundation pits from greatest to least were found to be as follows: Diaoyuzui Station > Tianfu CBD North Station $>$ Xinchuan Science Park East Station.

During the 2018 flood season in Chengdu, Diaoyuzui Station was the most severely damaged of all the 22 station projects. Tianfu CBD North Station was the second-most damaged, but Xinchuan Science Park East Station was hardly affected by this flood disaster. The actual disaster situations of the three deep foundation pit projects from greatest to least were therefore as follows: Diaoyuzui Station > Tianfu CBD North Station $>$ Xinchuan Science Park East Station Project. This ranking obtained by the on-site investigation was consistent with the waterlogging risk results calculated by the method proposed in this study. The consistency proves that the proposed method is both objective and effective.

\subsubsection{Measures to Address Waterlogging Risk in Deep Foundation Pit Projects}

(1) To better ensure construction safety, the deep foundation pit project of Diaoyuzui Station should deal with risks in accordance with the extreme risk (IV) level. Project managers should immediately suspend construction tasks and take steps to reduce the risk level. The construction operations of Tianfu CBD North Station and Xinchuan Science Park East Station do not require termination, but their project management staff should immediately formulate further measures to address waterlogging risk and decrease the level of waterlogging risk as soon as possible.

(2) In the design and planning of the construction organization of deep foundation pit projects, the local hydrometeorological data, especially the data of regional annual rainfall frequency and the largest rainfall intensity in history, should be fully investigated. During construction, project managers should consider future climate changes and adjust the measures for waterlogging risk according to the changes in weather.

(3) The managers of deep foundation pit projects should attach more importance to the preparation of emergency rescue plans. Before the flood season, they should conduct emergency rescue drills for waterlogging, strengthen the construction of rescue organizations, and improve the efficiency of emergency rescue.

(4) The proportion of older workers should be reduced to mitigate the vulnerability of the local population. However, in China, the aging of construction workers has become increasingly more severe in the past ten years, and it is a difficult task to reduce the proportion of older employees. Therefore, as an alternative measure, increasing emergency rescue training is recommended.

\section{Conclusions}

The intention of this study was to conduct an objective and effective evaluation of waterlogging risk in deep foundation pits based on the projection pursuit method. According to the process of water circulation and the characteristics of deep foundation pits, an evaluation index system with 11 indicators was constructed for the first time. Then, a combination of the projection pursuit method, particle swarm optimization, and the interpolation algorithm was used to construct a waterlogging risk assessment method. In this method, the projection pursuit method is used to handle the high-dimensional data of waterlogging risk assessment, and the optimal projection vector is solved by particle swarm optimization, which is characterized by relatively rapid and appropriate convergence. The mathematical function between the best projection values and the risk levels was constructed by an interpolation algorithm. Finally, three typical deep foundation pits of Chengdu Metro Line 11 were analysed, and some risk response strategies were provided based on the results of the case analysis. The results of the case study revealed that the frequency of storms, intensity of rainfall, preparation of emergency rescue plans, and proportion of older workers have the greatest impacts on the waterlogging risk in deep foundation pits. These four factors 
were also the key factors in the waterlogging disaster of Diaoyuzui Station during the 2018 flood season, and project management personnel should place focus on them in future waterlogging risk management and decision-making. The waterlogging risk ranking results of the three typical deep foundation pits calculated by the proposed method were basically congruent with the disaster situation in the 2018 flood season. Consequently, it can be concluded that the proposed method based on the projection pursuit method is both objective and effective. Future research will concentrate on the establishment of a unified waterlogging risk evaluation index system and the use of more soft computing methods for waterlogging risk evaluation.

\section{Data Availability}

The MATLAB programs and case analysis data used to support the findings of this study are available from the corresponding author upon request.

\section{Conflicts of Interest}

The authors declare that there are no conflicts of interest regarding the publication of this paper.

\section{Acknowledgments}

This study was supported by the National Key R\&D Program of China (2018YFC0704301) and the Science and Technology Project of Wuhan Urban and Rural Construction Bureau, China (201943).

\section{References}

[1] S. Tei, T. Morozumi, S. Nagai et al., "An extreme flood caused by a heavy snowfall over the Indigirka river basin in Northeastern Siberia," Hydrological Processes, vol. 34, no. 3, pp. 522-537, 2020.

[2] S. Liu, M. N. Lin, and C. L. Li, "Analysis of the effects of the river network structure and urbanization on waterlogging in high-density urban areas-a case study of the Pudong new area in Shanghai," International Journal of Environmental Research and Public Health, vol. 16, no. 18, Article ID 3306, 2019.

[3] H. Wu, "Research and discussion on urban waterlogging in Wuhan," Water Supply and Sewerage, vol. 53, no. 1, pp. 117-119, 2017.

[4] J. Hou and Y. Du, "Spatial simulation of rainstorm waterlogging based on a water accumulation diffusion algorithm," Geomatics, Natural Hazards and Risk, vol. 11, no. 1, pp. 71-87, 2020.

[5] J. X. Jia, X. Y. Wang, N. A. M. Hersi et al., "Flood-risk zoning based on analytic hierarchy process and fuzzy variable set theory," Natural Hazards Review, vol. 20, no. 3, Article ID 04019006, 2019.

[6] Z. N. Wu, Y. X. Shen, and H. L. Wang, "Assessing urban areas' vulnerability to flood disaster based on text data: a case study in Zhengzhou city," Sustainability, vol. 11, no. 17, Article ID 4548, 2019.

[7] H. Y. Yu, C. Liang, P. Li et al., "Evaluation of waterlogging risk in an urban subway station," Advances in Civil Engineering, Article ID 5393171, 2019.
[8] R. Mikaeil, S. Shaffiee Haghshenas, Y. Shirvand, M. Valizadeh Hasanluy, and V. Roshanaei, "Risk assessment of geological hazards in a tunneling project using harmony search algorithm (case study: Ardabil-Mianeh Railway tunnel)," Civil Engineering Journal, vol. 2, no. 10, pp. 546-554, 2016.

[9] D. T. Bui, N. D. Hoang, T. D. Pham et al., "A new intelligence approach based on GIS-based multivariate adaptive regression splines and metaheuristic optimization for predicting flash flood susceptible areas at high-frequency tropical typhoon area," Journal of Hydrology, vol. 575, pp. 314-326, 2019.

[10] R. Mikaeil, M. Beigmohammadi, E. Bakhtavar et al., "Assessment of risks of tunneling project in Iran using artificial bee colony algorithm," SN Applied Sciences, vol. 1, no. 12, Article ID 1711, 2019.

[11] P. Wei, F. Qiang, L. Dong et al., “Assessing agricultural drought vulnerability in the Sanjiang Plain based on an improved projection pursuit model," Natural Hazards, vol. 82, no. 1, pp. 683-701, 2016.

[12] Y. Sen and L. H. Wei, "An integrated model of water resources optimization allocation based on projection pursuit modelgrey wolf optimization method in a transboundary river basin," Journal of Hydrology, vol. 559, pp. 156-165, 2018.

[13] Y. Liang, D. Guo, Z. Huang, and X. Jiang, "Prediction model for coal-gas outburst using the genetic projection pursuit method," International Journal of Oil, Gas and Coal Technology, vol. 16, no. 3, pp. 271-282, 2017.

[14] D. Liu, G. D. Zhang, and H. Li, "Projection pursuit evaluation model of a regional surface water environment based on an Ameliorative Moth-Flame Optimization algorithm," Ecological Indicators, vol. 107, no. 1, Article ID 105674, 2019.

[15] Y. S. Jiang, D. Zhao, D. D. Wang et al., "Sustainable performance of buildings through modular prefabrication in the construction phase: a comparative study," Sustainability, vol. 11, no. 20, Article ID 5658, 2019.

[16] S. Li, C. Jiang, and A. Li, "Research on Chinese well-known e-commerce enterprises' innovation ability based on real comment," International Journal of Computing Science and Mathematics, vol. 11, no. 1, pp. 54-62, 2020.

[17] W. J. Zhang, F. Wei, R. Zhou et al., "Risk assessment of cotton textile enterprise working environment based on projection pursuit model," China Safety Science Journal, vol. 28, no. 4, pp. 103-108, 2018.

[18] A. Kukker and R. Sharma, "Genetic algorithm-optimized fuzzy lyapunov reinforcement learning for nonlinear systems," Arabian Journal for Science and Engineering, vol. 45, no. 3, pp. 1629-1638, 2020.

[19] R. Bendaoud, H. Amiry, M. Benhmida et al., "New method for extracting physical parameters of PV generators combining an implemented genetic algorithm and the simulated annealing algorithm," Solar Energy, vol. 194, pp. 239-247, 2019.

[20] R. Mikaeil, S. Shaffiee Haghshenas, and Z. Sedaghati, "Geotechnical risk evaluation of tunneling projects using optimization techniques (case study: the second part of Emamzade Hashem tunnel)," Natural Hazards, vol. 97, no. 3, pp. 1099-1113, 2019.

[21] A. R. Dormishi, M. Ataei, R. K. Kakaie et al., "Performance evaluation of gang saw using hybrid ANFIS-DE and hybrid ANFIS-PSO algorithms," Journal of Mining and Environment, vol. 10, no. 2, pp. 543-557, 2019.

[22] M. Hasanipanah, R. Naderi, J. Kashir, S. A. Noorani, and A. Zeynali Aaq Qaleh, "Prediction of blast-produced ground vibration using particle swarm optimization," Engineering with Computers, vol. 33, no. 2, pp. 173-179, 2017. 
[23] P. Ronco, V. Gallina, S. Torresan et al., "The KULTURisk regional risk assessment methodology for water-related natural hazards-part 1: physical-environmental assessment," Hydrology and Earth System Sciences, vol. 18, no. 12, pp. 5399-5414, 2014.

[24] P. Cui and D. Li, "Measuring the disaster resilience of an urban community using ANP-FCE method from the perspective of capitals," Social Science Quarterly, vol. 100, no. 6, pp. 2059-2077, 2019.

[25] Y. Zhou, N. Li, W. Wu, and J. Wu, "Assessment of provincial social vulnerability to natural disasters in China," Natural Hazards, vol. 71, no. 3, pp. 2165-2186, 2014.

[26] Y. Wei and O. Linet, "A dynamic logistics coordination model for evacuation and support in disaster response activities," European Journal of Operational Research, vol. 179, no. 3, pp. 1177-1193, 2007.

[27] M.-S. Chang, Y.-L. Tseng, and J.-W. Chen, "A scenario planning approach for the flood emergency logistics preparation problem under uncertainty," Transportation Research Part E: Logistics and Transportation Review, vol. 43, no. 6, pp. 737-754, 2007.

[28] E. L. Guo, J. Q. Zhang, Y. F. Wang et al., "Dynamic risk assessment of waterlogging disaster for maize based on CERES-Maize model in Midwest of Jilin province, China," Natural Hazards, vol. 83, no. 3, pp. 1747-1761, 2016.

[29] X. Liu and H. Chen, "Integrated assessment of ecological risk for multi-hazards in Guangdong province in southeastern China," Geomatics, Natural Hazards and Risk, vol. 10, no. 1, pp. 2069-2093, 2019.

[30] Y. L. Liang, Y. L. Wang, Y. J. Zhao et al., "Analysis and projection of flood hazards over China," Water, vol. 11, no. 5, Article ID 1022, 2019.

[31] M. Ma, H. Wang, P. Jia et al., "Investigation of inducements and defenses of flash floods and urban waterlogging in Fuzhou, China, from 1950 to 2010," Natural Hazards, vol. 91, no. 2, pp. 803-818, 2018.

[32] D. Liu, C. Liu, Q. Fu et al., "Projection pursuit evaluation model of regional surface water environment based on improved chicken swarm optimization algorithm," Water Resources Management, vol. 32, no. 4, pp. 1325-1342, 2018.

[33] J. Zhao, J. Jin, Q. Guo, L. Liu, Y. Chen, and M. Pan, "Dynamic risk assessment model for flood disaster on a projection pursuit cluster and its application," Stochastic Environmental Research and Risk Assessment, vol. 28, no. 8, pp. 2175-2183, 2014.

[34] S. Wang, X. Zhang, Z. Yang, J. Ding, and Z. Shen, "Projection pursuit cluster model based on genetic algorithm and its application in Karstic water pollution evaluation," International Journal of Environment and Pollution, vol. 28, no. 3/4, pp. 253-260, 2006.

[35] D. Liu, J. P. Feng, H. Li et al., "Spatiotemporal variation analysis of regional flood disaster resilience capability using an improved projection pursuit model based on the wind-driven optimization algorithm," Journal of Cleaner Production, vol. 241, Article ID 118406, 2019.

[36] X. Huang and H. Bai, "Risk prediction of rural public security environmental carrying capacity based on the risk entropy," Natural Hazards, vol. 90, no. 1, pp. 157-171, 2018.

[37] Z. Lan and M. Huang, "Safety assessment for seawall based on constrained maximum entropy projection pursuit model," Natural Hazards, vol. 91, no. 3, pp. 1165-1178, 2018.

[38] J. H. Yuan and C. B. Li, "Intuitionistic trapezoidal fuzzy group decision-making based on prospect choquet integral operator and grey projection pursuit dynamic cluster," Mathematical
Problems in Engineering, vol. 2017, Article ID 2902506, 13 pages, 2017.

[39] C. Qi, A. Fourie, Q. Chen et al., "Neural network and particle swarm optimization for predicting the unconfined compressive strength of cemented paste backfill," Construction and Building Materials, vol. 159, pp. 473-478, 2018.

[40] X. H. Yang, Z. F. Yang, Z. Y. Shen et al., "Interpolation model for flood disaster assessment based on projection pursuit," Disaster Science, vol. 4, pp. 3-8, 2004.

[41] J. E. Ware, M. Kosinski, and S. D. Keller, "A 12-item shortform health survey," Medical Care, vol. 34, no. 3, pp. 220-233, 1996.

[42] J. J. Liang, A. K. Qin, P. N. Suganthan, and S. Baskar, "Comprehensive learning particle swarm optimizer for global optimization of multimodal functions," IEEE Transactions on Evolutionary Computation, vol. 10, no. 3, pp. 281-295, 2006.

[43] N. Lynn and P. N. Suganthan, "Heterogeneous comprehensive learning particle swarm optimization with enhanced exploration and exploitation," Swarm and Evolutionary Computation, vol. 24, pp. 11-24, 2015.

[44] Z. H. Zhan, J. Zhang, Y. Li, and H. S.-H. Chung, "Adaptive particle swarm optimization," IEEE Transactions on Systems Man and Cybernetics Part B-Cybernetics, vol. 39, no. 6, pp. 1362-1381, 2009.

[45] A. Berro, S. Larabi Marie-Sainte, and A. Ruiz-Gazen, "Genetic algorithms and particle swarm optimization for exploratory projection pursuit," Annals of Mathematics and Artificial Intelligence, vol. 60, no. 1-2, pp. 153-178, 2010.

[46] R. J. Bolton and W. J. Krzanowski, "Projection pursuit clustering for exploratory data analysis," Journal of Computational and Graphical Statistics, vol. 12, no. 1, pp. 121-142, 2003.

[47] A. I. Gorshkov, H. M. Hassan, and O. V. Novikova, "Seismogenic nodes $(M \geq 5.0)$ in northeast Egypt and implications for seismic hazard assessment," Pure and Applied Geophysics, vol. 176, no. 2, pp. 593-610, 2019. 